\title{
History of Red-crowned Crane Grus japonensis and its habitats in China
}

\author{
ZHIJUN MA, ZIJIAN WANG and HONGXIAO TANG
}

\section{Summary}

The historical distribution of the Red-crowned Crane Grus japonensis together with changes in its breeding and wintering grounds in China are reviewed. According to historical information the bird mainly bred in Heilongjiang and Jilin Provinces and wintered at coastal regions near the Yangtze estuary. Due to geographical and anthropological changes, the breeding grounds gradually moved to the west and south while the wintering grounds moved northward. Efforts have been made to protect this endangered species but factors still exist which restrict further development of the population.

\section{Introduction}

The Red-crowned Crane Grus japonensis is one of the most endangered birds in the world. Its breeding grounds include parts of China, Japan, Korea and Siberia while the species winters largely along the coasts and in the wetlands of the middle and lower reaches of the Yangtze River. A resident population has been reported in Japan. In 1994 the world population of Red-crowned Cranes was estimated at about 1,050-1,200 (Collar et al. 1994) with over half in China.

Due to its rarity the species was included in the "Red list of threatened species" and was classified as vulnerable (World Conservation Monitoring Centre 1994). It was also classified as in need of special protection by the Chinese government.

There is much literature, particularly since the 1980s, devoted to the Red-crowned Crane. There have been studies of its breeding ecology (Yao 1984, Chen and Sun 1986, Li 1987, Duan and Du 1987), its distribution (Ding and Zhou 1982, Tong and Wen 1986, Tong and Tong 1986, Ma et al. 1987, Lu 1989, Pu and Li 1990), abundance (Ma and Xu 1980, Feng 1985, Ma and Jin 1986, Ma et al. 1987, Lu 1988, Liu 1990), and wintering ecology (Shi and $\mathrm{Wu}$ 1987, Yan 1991). There have also been studies of captive breeding (Gan and Song 1984, Jiang 1984) and of conservation management ( $\mathrm{Lu}$ 1995). The major concern is loss of habitats due to regional economic development.

\section{Red-crowned Crane in China}

In ancient China the Red-crowned Crane was a symbol of longevity, fortune and dignity and its importance was recognized when the Chinese government established the first nature reserve in Zhalong, Heilongjaing Province in 1979, 
Table 1 . Established nature reserves for the protection of Red-crowned Crane in China

\begin{tabular}{lclc}
\hline Official name & $\begin{array}{c}\text { Date of } \\
\text { establishment }\end{array}$ & Location & $\begin{array}{c}\text { Area } \\
\left(\mathrm{km}^{2}\right)\end{array}$ \\
\hline Zhalong Nature Reserve & 1979 & Chichihar, Heilongjiang Province & 2,100 \\
Momoge Nature Reserve & 1981 & Zhenlai, Jilin Province & 1,440 \\
Xianghai Nature Reserve & 1981 & Tongyu, Jilin Province & $1,046.7$ \\
Yancheng Nature Reserve & 1983 & Yancheng, Jiangsu Province & 4,530 \\
Honghe Nature Reserve & 1984 & Tongjiang, Heilongjiang Province & 163.3 \\
Shuangtaihekou Nature Reserve & 1985 & Dawa, Liaoning Province & 800 \\
\hline
\end{tabular}

'Wintering area, others are breeding areas.

the principal breeding ground of the species. Other reserves have since been established at both breeding and wintering grounds (Table 1, Figure 1). In 1987 an international crane symposium was held in China where efforts to protect the Red-crowned Crane were highlighted and encouraged.

In 1976 the first reported number of Red-crowned Cranes in Heilongjiang Province was 1,310 (Ma and Xu 1980). In 1981 the total number of birds in China was estimated at 1,300 and, following a steady decline, the number had dropped to 520 by 1986 .

Table 2 gives the number of Red-crowned Cranes wintering in the Yancheng Nature Reserve which holds the majority of the cranes in China at this time of year.

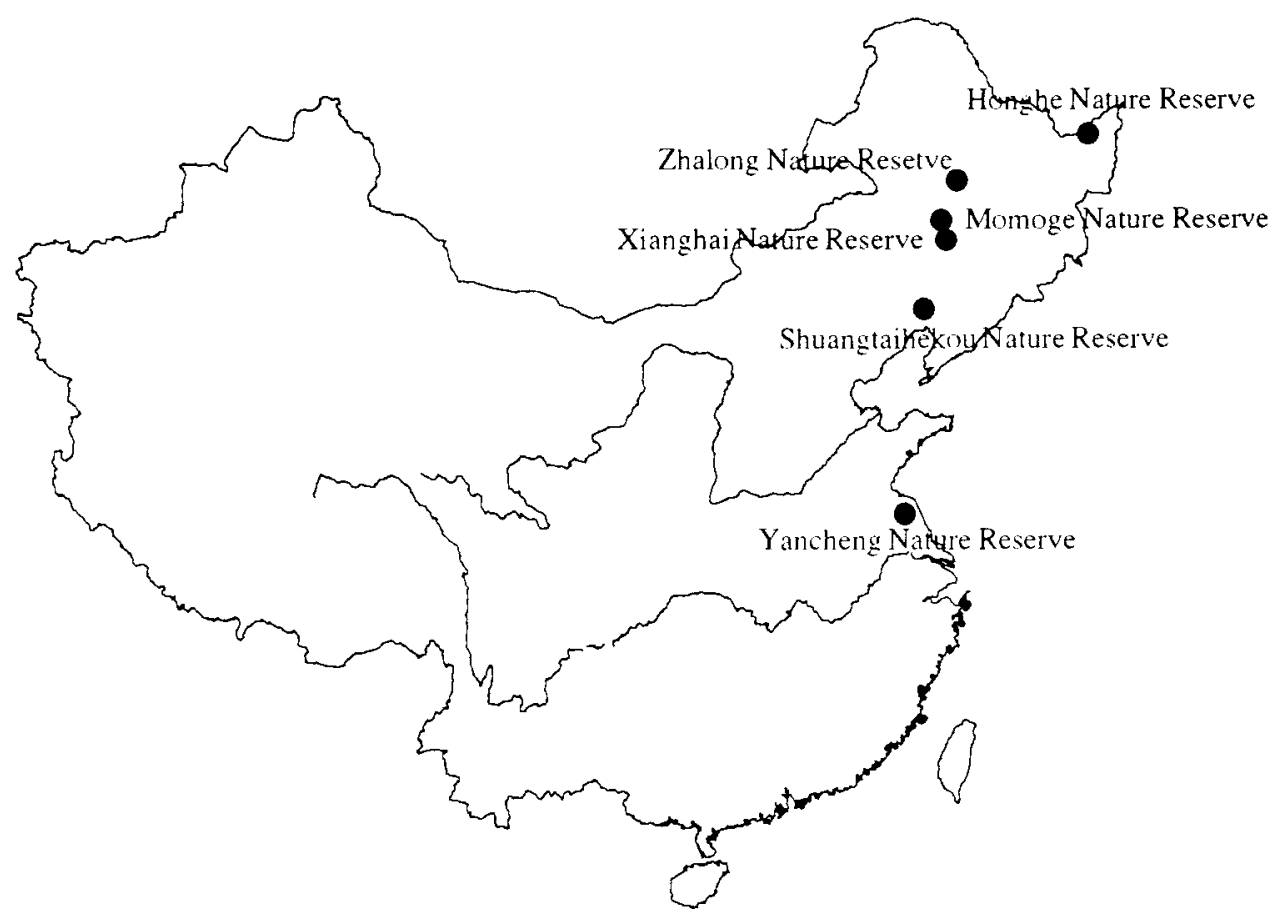

Figure 1. Geographical locations of nature reserves for Red-crowned Cranes in China. 
Table 2. Variation in number of Red-crowned Cranes (1976-1995) in China compared with the world population

\begin{tabular}{lccl}
\hline Year & $\begin{array}{c}\text { In breeding grounds } \\
\text { in China }\end{array}$ & $\begin{array}{c}\text { In wintering grounds } \\
\text { in China }\end{array}$ & \multicolumn{1}{l}{ In the world } \\
\hline 1976 & $\mathbf{1}, 310^{k}$ & - & - \\
1981 & $\mathbf{1} 300$ & 444 & $\mathbf{1 , 6 3 1}$ \\
1984 & 700 & 575 & $\mathbf{1 , 2 0 0}$ \\
1985 & 616 & 616 & - \\
1986 & 520 & 876 & $\mathbf{1 , 0 0 0}$ \\
1994 & - & 707 & $\mathbf{1 , 0 5 0 - 1 , 2 0 0}$ \\
1995 & - & 789 & $\mathbf{1 , 5 0 0}$ \\
\hline
\end{tabular}

"In Yancheng Nature Reserve. There are probably other wintering grounds with much smaller numbers of birds.

In Heilongjiang Province.

Date sources: Ma and Xu 1980, Tong and Wen 1986, Ma et al. 1987, Lu 1989, Pu and Li 1990, Yan 1991, Collar et al. 1994.

\section{History of breeding grounds of Red-crowned Crane in China}

The breeding grounds of the Red-crowned Crane have been recorded since 1443 and as Heilongjaing Province was known as the native land of the crane, it seems likely that this was an important region for the species until the early 190os. The literature also indicates that cranes were exported from this region to be reared in captivity.

In Jilin Province in the mid-19oos distribution of the species was considered extensive with many birds found on the banks of the Taor River, the Songhuajiang River and the lower reaches of the Huolin River. In the 1960 s breeding populations were recorded at Moon Lake and Chagan Lake as well as on the banks of the Songhuajiang and Nenjiang rivers in north-east China (Tong and Wen 1986). Following the creation of artificial reedbeds near the mouth of the Shuangtaihe River in the 1950s, a small number of cranes bred in Liaoning Province, an area thought to have been used by migrating birds in ancient times (Chen and Sun 1986). Overall the species was considered as widespread, even in the mid-190os, in north-east China (Figure 2).

In recent years the breeding grounds of cranes have been reduced because land is being used for industry and agriculture. The major breeding grounds are now located in the Sanjiang Plain and along the middle and downstream stretches of the Nenjiang River in Heilongjiang Province; these areas now support over half the population of cranes in China. Other breeding grounds include a narrow belt from Xianghai downstream along the Huolin River in Jilin Province. In addition to Heilongjaing and Jilin Provinces, new breeding grounds of cranes have been reported in Dawa County in Liaoning Province, Zhaowudameng, Zhelimumeng and also Xinganmeng in the Inner Mongolia Autonomy (Chen and Sun 1986, Tong and Tong 1986). It is possible that the cranes are trying to establish breeding grounds to the south and west of former sites (Figure 2).

As seen in Figure 2, historically the large breeding areas of Red-crowned Crane were in Heilongjiang and Jilin Provinces and these remain the major breeding areas today, but with reductions in suitable habitat. The birds have established 


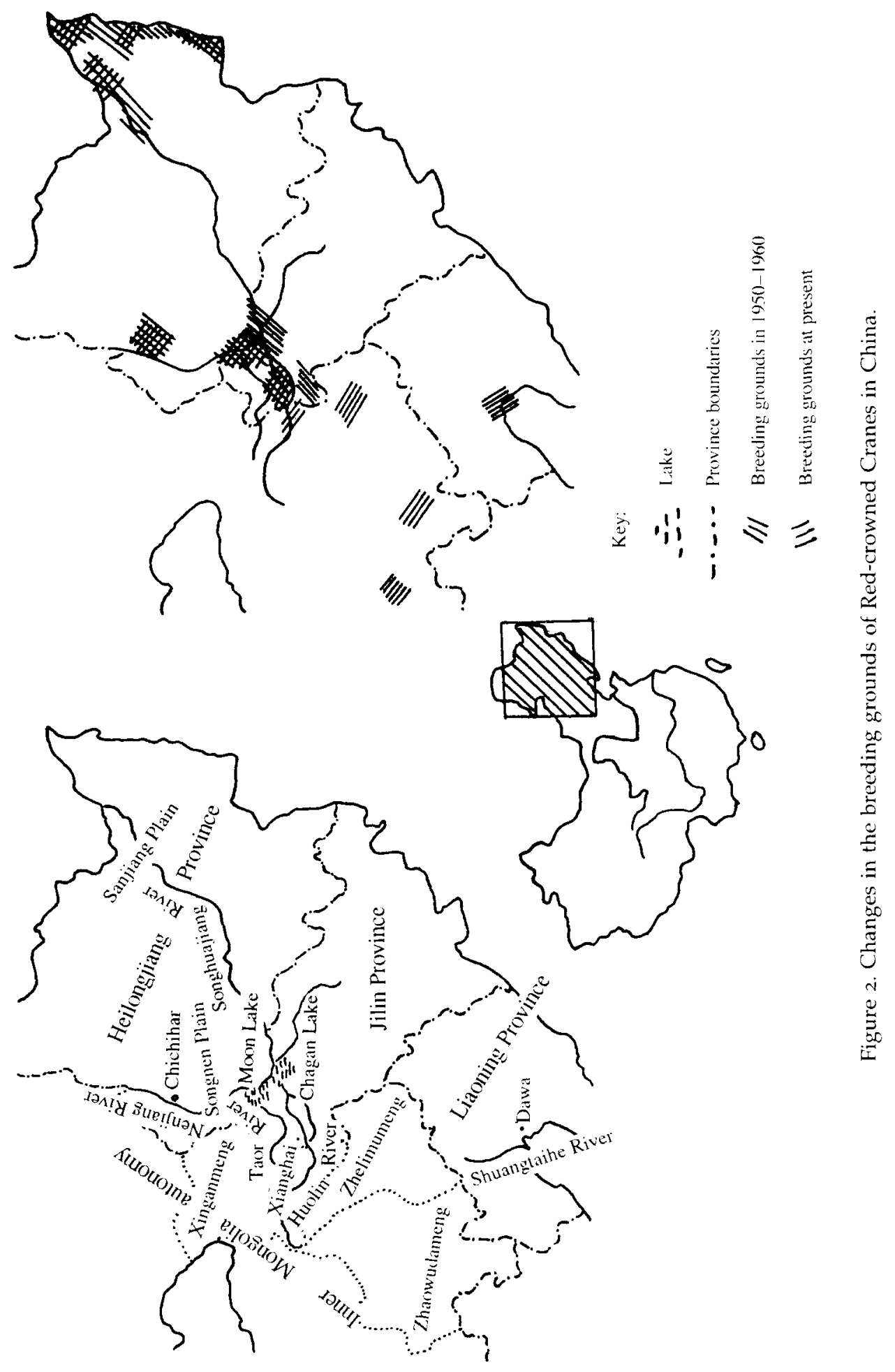


new breeding grounds to the west and south in Liaoning Province and the Inner Mongolia Autonomy. Further expansion could be expected to the Songnen Plain in the west and the Sanjiang Plain in the east which should provide suitable breeding habitat with flat ground, slow water flow and abundant wetlands.

\section{History of wintering grounds of Red-crowned Cranes in China}

The historical and current wintering areas of Red-crowned Crane are shown in Figure 3. A comparison of past and recent records shows that the wintering grounds of the Red-crowned Crane have changed significantly. From the Sanguo Dynasty (A.D. 220-280) to the Song Dynasty (960-1279) records indicate that the main wintering grounds were in Songjiang Canton and Jiaxing Canton south of the Yangtze River delta. In the early Iooos, the coastline of the south shore of the Yangtze River was extended stretching from the eastern shore of the Huangpu River to the south-east and this led to eastward changes in the wintering grounds of the cranes. Land reclamation moved the coast eastwards until the end of the Ching Dynasty (1644-1911) but then stabilized and the Shanghai area expanded through both urbanization and human population. It seems that the crane, frequent during the Song Dynasty, was rare by the end of the Ching Dynasty.

From the mid-13oos until the beginning of this century a major wintering ground was around Lyusi, known as "the town of the crane", north of the Yangtze delta. Famous for its salt works, the associated grasslands and tidal stretches provided important wintering grounds for cranes. However, extensive exploitation of coastal land occurred in the early 1990 s and most of the wintering grounds at Lyusi were transformed into agricultural land. In addition the course change of the Yellow River brought more land into agricultural production with the concurrent destruction of wetlands. By the early 1900s the centre for wintering cranes had changed to regions near the Sheyang estuary where the soil was not suitable for farming.

Wintering cranes were also found on inland lakes in the middle and lower reaches of the Yangtze River. Historical records include Poyang, Dongting and Taihu Lakes while the species was recorded at Poyang Lake and at lakes in Anhui Province in more recent times (Ding and Zhou 1982, Ding 1985). Land reclamation has reduced the habitat available for cranes. For example between 1950 and 1980 the area of lakes decreased by $77 \%$ in the Jianghan Plain (Figure 3 ).

Recently the tidal areas in the north of Jiangsu Province have been expanding to produce new wetlands. These regions, around Yancheng City, have become a main wintering ground for cranes (Figure 3). There are $2,400 \mathrm{~km}^{2}$ of tidal mudflats with reedbeds transected by rivers. In 1983 the region was established as a reserve and increasing numbers of Red-crowned Cranes winter there (Table 2).

Only limited numbers of cranes winter in other inland areas. Sites include Chengdong Lake, Shijiu Lake and Laizi Lake in Anhui Province (Ding and Zhou 1982), Shaobao Lake in Jiangsu Province (Ding and Zhou 1982, Yan 1986), the region between Yancheng and Yangzhou cities, the upstream areas of Sheyang River, the environs of Hongze Lake (Ding and Zhou 1982) and the sea shores of Rizhao City in Shandong Province (Ji and Yu 1990) which represent the northern limit for wintering cranes. Birds reported from Yunnan Province and from Taiwan are probably vagrants (Wang and Wu 1986, Chen 1984). 


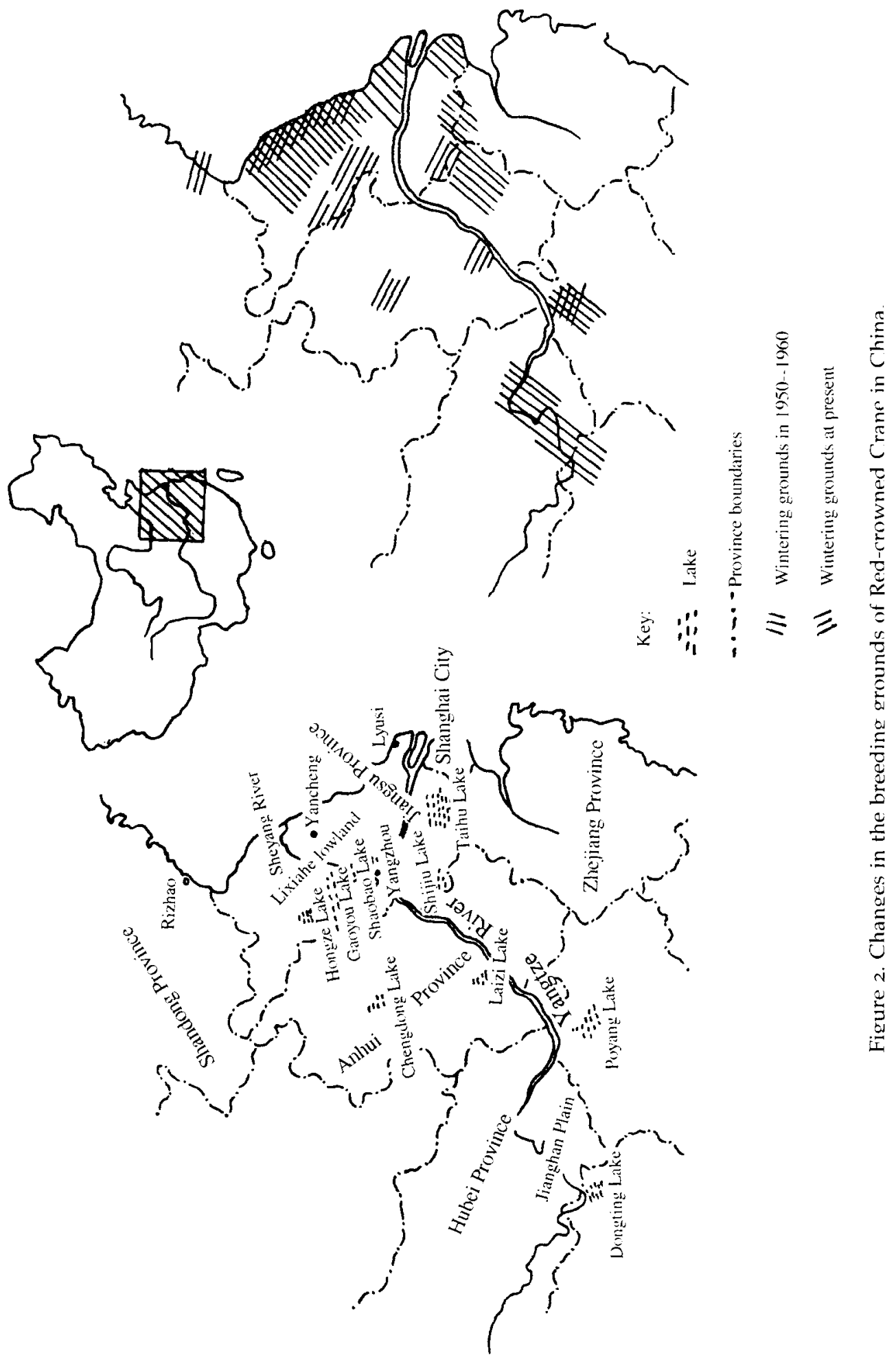


Table 3. The percentage of juvenile Red-crowned Cranes in the population wintering in the Yancheng Nature Reserve

\begin{tabular}{llllll}
\hline & 1986 & 1989 & 1990 & 1991 & 1995 \\
\hline Juveiles $(\%)$ & 19.90 & 20.28 & 17.61 & 21.50 & 22.05 \\
\hline
\end{tabular}

\section{Future prospects for the Red-crowned Crane in China}

The percentage of juvenile cranes in the wintering population at the Yancheng Reserve averaged 17-22\% between 1986 and 1995 (Table 3). This indicates good breeding success. Loss of habitat is the major threat to the crane population. At the breeding grounds water shortage has led to the drying of wetlands and the management of reedbeds has resulted in the loss of resting sites and shelter. On the wintering grounds habitat is lost due to reclamation of tidal lands, the construction of salt works and other industries. Rapid development of both agriculture and industry has led to the introduction of chemical pollutants. This is a particular problem in the Yancheng Reserve where birds are affected by agricultural chemicals.

\section{Acknowledgements}

We are grateful for the support of the Yancheng Nature Reserve which provided some of the information and documents included in this study. Thanks are also due to the Chinese National Committee for Man and Biosphere (MAB) programme for their support.

\section{References}

Chen, J. S. (1984) The vertebrates in Taiwan (2nd edn). Taipei: Taiwan Trade Publishing House.

Chen, T. S. and Sun, S. D. (1986) A survey of Red-crowned Crane breeding grounds in Liaoning Province. Pp. 58-64 in The collected works about cranes in China. Harbin: Heilongjiang Educational Publishing House.

Collar, N. J., Crosby, M. J. and Stattersfield, A. J. (1994) Birds to watch 2: the world list of threatened birds. Cambridge, U.K.: BirdLife International (BirdLife Conserv. Ser. 4).

Ding, T. M. (1985) The cranes in Poyang Lake. Wild Anim. 2: 22-23.

Ding, W. N. and Zhou, F. Z. (1982) The distribution of wintering cranes in China. Chin. J. Zool. $17(6)$ : 13-14.

Duan, W. R. and Du, X. D. (1987) The breeding record of the Red-crowned Crane in Dalinor. Chin. J. Zool. 22(3): 15.

Feng, K. M. (1985) The aerial investigation of waterfowls besides Red-crowned Crane. Northeast For. Univ. Bull. 13(1): 80-87.

Gan, S. Y. and Song, F. J. (1984) The breeding of cranes. Wild Anim. 4: 42-46.

Ji, J. Y. and Yu, J. X. (1990) The distribution and number of storks and cranes in Shandong Province. Chin. J. Zool. 25(1): 46-53.

Jiang, F. L. (1984) The selection of couples of Red-crowned Cranes. Wild Anim. 6: 54-55.

Li, J. L. (1987) Researching on the distribution of breeding grounds for Red-crowned Crane. Wild Anim. 2: 11-14.

Liu, B. (1990) The number and distribution of Red-crowned Crane wintering on the tidal lands of Yancheng, Jiangsu Province. Acta Ecol. Sci. 1o(3): 284-285.

Lu, S. C. (1988) The change of number and distribution of Red-crowned Crane wintering in the seaside of Yancheng, Jiangsu Province. Sichuan Anim. 7: 13-15. 
Lu, S. C. (1989) The distribution of Red-crowned Crane in Yancheng. Wild Anim. 1: 19-21.

$\mathrm{Lu}$, S. C. (1995) The relation between protection of rare animals and economic development in seaside of Yancheng, Jiangsu Province. Chin. Biosphere Res. 4: 13-15.

Ma, G. E. and $\mathrm{Xu}, \mathrm{S}$. Q. (1980) The primary discussion on the census investigations of Red-crowned Crane. Wild Anim. 1: 4-7.

Ma, Y. Q. and Jin, L. R. (1986) The number and distribution of Red-crowned Crane in Heilongjiang Province. Pp. $45^{-53}$ in The collected works about cranes in China. Harbin: Heilongjiang Educational Publishing House.

Ma, Y. Q., Jin, L. R., Jin, A. L. and Fu, C. Z. (1987) The investigation report of rare fowls besides Red-crowned Crane in Wuyur river basin, Heilongjiang Province. Chin. Zool. Bull. 33(4): 187-191.

Pu, R. Z. and Li, W. F. (1990) The Red-crowned Crane in Xinghai Lake. Pp. 76-77 in Protection and researching of cranes of the world. Beijing: Chinese Forestry Publishing House.

Shi, Z. R. and Wu, L. X. (1987) The habits of Red-crowned Crane in winter. Wild Anim. 1: 20-21.

Tong, Y. C. and Tong, J. C. (1986) The investigation report of cranes in four eastern allies in Inner Mongolia. Pp. 212-213 in The collected works about cranes in China. Harbin: Heilongjiang Educational Publishing House.

Tong, Y.C. and Wen, C. C. (1986) The distribution and number of Red-crowned Crane in Jilin Province. Pp. 54-57 in The collected works about cranes in China. Harbin: Heilongjiang Educational Publishing House.

Wang, Z. J. and Wu, J. L. (1986) The distribution of cranes in Yunnan Province. Pp. 216218 in The collected works about cranes in China. Harbin: Heilongjiang Educational Publishing House.

World Conservation Monitoring Centre (1994) Red list of threatened species. Gland, Switzerland: IUCN.

Yao, L. W. (1984) The breeding record of Red-crowned Crane in Liaoning Province. Chin. Zool. Res. 5(2): 180 .

Yan, A. H. (1986) The Red-crowned crane wintering in north Jiangsu Province. Chin. J. Zool. 21(5): 31-32.

Yan, F. T. (1991) Research on the number, distribution and ecology of Red-crowned Crane wintering on tidal lands in Yancheng. Chin. J. Zool. 26(2): 34-36.

N.B. All references by Chinese authors are written in Chinese.

ZHIJUN MA, ZIJIAN WANG and HONGXIAO TANG

SKLEAC, Research Centre for Eco-Environmental Sciences, Chinese Academy of Sciences, P.O. Box 2871, Beijing, 100085, P.R.C. 